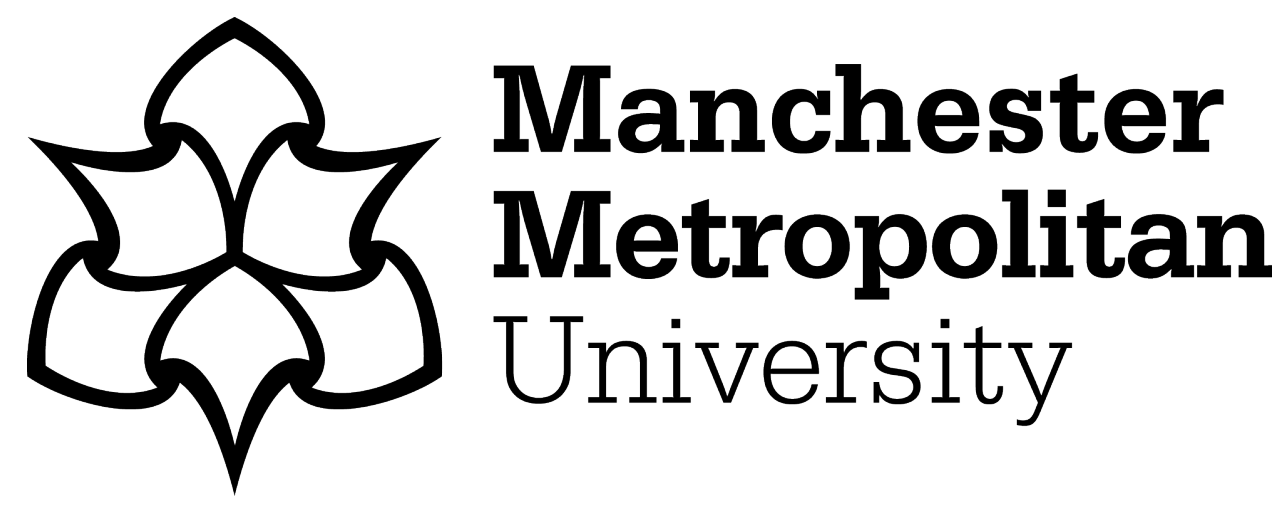

Miles, S ORCID logoORCID: https://orcid.org/0000-0002-3317-1151 (2019) Immersive narratives of 'self-work' in an experience society: understanding the cruise ship experience. Leisure Studies, 38 (4). pp. 523-534. ISSN 0261-4367

Downloaded from: https://e-space.mmu.ac.uk/622855/

Version: Accepted Version

Publisher: Taylor \& Francis

DOI: https://doi.org/10.1080/02614367.2019.1597148

Please cite the published version 


\title{
Immersive narratives of 'self-work' in an experience society: understanding the cruise ship experience
}

\author{
Steven Miles \\ Manchester Metropolitan University, Manchester, UK
}

\begin{abstract}
Commentators have long argued that cruise ship tourism is a highly rationalised form of mass consumption, a 'total institution' in which consumption defines and controls the individual's experience. Arguing that this represents a simplification, this article suggests that a closer analysis of cruise tourism tells us something profound about the nature of what it means to be a consumer in a deterritorialised age. Specifically, the article explores the suggestion that the cruise experience represents a mode of consumption in which the consumer effectively becomes the product. Through the deployment of an autoethnographic investigation of the cruising experience the paper seeks to shed light on the relationship between the tourist experience and notions of self, while making a case for a reconceptualisation of consumption as self-work. In this light, the contention is made that the ideological power of consumption is intensified by tourism's emphasis on the experience of the consumer as part of a broader process in which there has been a shift away from the specific consumption of products towards consumption as a temporal-partial process of self-endowment.
\end{abstract}

ARTICLE HISTORY

Received 26 October 2018

Accepted 11 March 2019

\section{KEYWORDS}

Cruise ships; consumption; identity; experience; autoethnography

The emergence of the cruise ship experience has perhaps been the most significant single development in the tourism industry in the past twenty years. There is no questioning the numbers: the global capacity for cruise ships rose from 17.8 million passengers in 2009 to 24.2 million in 2016 while between 2008 and 2014, cruise travel outpaced general leisure travel in the U.S. by 22\% with an estimated global economic impact of $\$ 119.9$ billion (Cruise Lines International Association, 2018). The sheer rate at which ships are being built (around 27 per year according to latest figures) and the size of those ships is testament to a context in which the experience of the cruise ship as a resort destination in its own right has arguably become an even more urgent consideration for the tourist than maximizing the benefits of the ship's port of call (Wood, 2008). In this article, I contend that although the cruise experience may boast elements of a highly rationalised and controlled mass tourism, deeper beneath the surface its development says something more profound about the changing nature of what it means to be a consumer. Specifically, I will consider the suggestion that the cruise experience represents a mode of consumption in which the consumer effectively becomes the product (Klingmann, 2007). By doing so I will reconsider the relationship between the tourist and their experience of consumption, while making a case for a re-conceptualization of consumption as 'self-work': the way in which consumers use consumption to actively contribute to a sense of who they are and how it is they relate to the uncertain world around them (Brown, 2015).

\section{Consumption as self-work}

In what follows I will seek to understand cruising as a form of self-work that the tourist undertakes in de-territorialized space. I argue that the sociological significance of the cruise ship lies in 
its ability to separate itself from historically-rooted space, while being comprehensively subjected to outside market-driven forces (Wood, 2008), and thus simultaneously mirrroring and perhaps reinforcing some of the broader processes going on in a consumer society. Indeed, as Cremin (2011) suggests, a consumer ethic is by its very nature disconnected from space. In effect, I want to consider the cruise ship as an economic space, detached from the constraints of local culture while reproducing and maximizing aspects of more generic cultural forms as a means of maximising consumption opportunities. As such, I will argue that it is through the simultaneously constraining and enabling nature of cruise consumption, and the other-worldly experience that this entails, that the role of consumption as 'self-work' is maximised. In this context, I argue that 'self-work' provides an essential and currently under-utilised lens through which the tourism experience and consumption more broadly can be better understood in an ideological context.

As Collareo (2003) notes the symbolic and the communicative strategies employed by consumers in the construction of self-meanings have long been a concern for social scientists, not least as a result of the subjectivisation of the individual by capitalism (see Moran, 2014). For the purposes of this article my focus is on 'self-work' which is defined here as the means by which a sense of an individual's inner psychological being is made real via whatever social context or experiences the individual might partake in that makes this feel real. Leisure (and by implication tourism) constitutes a category over-written by the logic of self-improvement. The desire for selfimprovement that we explore through tourism is harnessed by consumer capitalism as an engine of economic and social reproduction (Smith Maguire, 2008). A key element of this process is what Elliott (2016) refers to as 'identity reengineering' or what Moran (2014) describes as subjectivisation: a state of affairs in which the fashioning of do-it-yourself biographies have become paramount. It's in this sense that experiential consumption, as illustrated for example, by Prentice's (2001) discussion of cultural tourism, goes about offering the consumer what appears to be a nonpackaged and individualised experience in the form of 'a personal revelation every time you visit'. Such personalisation is a crucial aspect of self-work under the guise of consumer capitalism given that the individual is expected to transform him or her self and needs to be seen to be doing so.

For many authors tourism lies at the centre of this process of self-transformation. In this context, Breathnach (2006) argues that the tourist is preoccupied with finding an existential state of being, and reflects on turn in Selwyn's (1996) contention that through tourism the self seeks a form of immediate gratification that frees them up from social and moral constraints. An individual thus immerses themselves in the amplified experiential situation that tourism provides (Breathnach, 2006). For Breathnach there is something particularly empowering, for example, about the collective narratives that heritage centres provide, while filling in some of the gaps that exist in individualised narratives of self. Similarly, Noy (2004) argues that backpackers who describe a deep and profound sense of personal change as a result of their travels, aspire to the freedoms that the liminal spaces they explore can apparently offer them. Indeed, 'authenticty, and the adventurous experiences therein, allow for narratives of identity to be told, through the claim of a lasting self-change. Authenticity here is best conceptualised as a commodity, which the tourists consume and employ.' (p. 96) The implication here then is that the escape that tourism represents, whether authentic or not, provides the individual with a sense of stability through transformation. It allows the individual to maintain a sense of control of who they are in a world in which they might otherwise rarely do so.

I will now go on to focus on cruising as a de-territorialized space in which the above characteristics are intensified. More specifically, I want to consider the proposition that cruise tourism constitutes a form of experiential consumption that may be indicative of the way how we consume is changing: that how we consume experience props up our sense of stability, and in doing so convinces the individual that he or she is the beneficiary of a secure sense of who or what they are. It's in light of such a realisation that this article constitutes an attempt to endorse an agenda that balances an understanding of the relationship between identity, tourism and social change and which thus more readily acknowledges the complexities and paradoxes of meaningmaking. 


\section{The cruise ship experience}

The cruise ship experience has perhaps surprisingly attracted limited interest on the part of social scientists. Although some authors have addressed the role of consumption in the democratisation of tourism, the cruise ship has rarely been at the centre of this analysis (see Miles, 2010). Those commentators that have considered the significance of cruising have tended to focus on the rationalised nature of the cruise experience. It is in this respect, that Ritzer (2010) goes as far as to describe the cruise ship as a 'total institution' given that passengers, '... cannot leave the ship while at sea, they can only do what is available to them on board, and they can only consume when and what the ship offers' (pp. 92-93). As such, Kolberg (2016, p. 98) discusses the way in which cruise ships democratise desire and deliver the consumer from the mundane, through the 'purported naturalism' that consumption can offer. The cruise ship is a space devoid of social context beyond that defined by the ability to consume: a space that firmly establishes the principle that human activity or endeavour must always be defined through a specific image of the economic (Brown, 2015). I want to suggest here that such an approach is at least partly misleading: that although the cruise ship constitutes a laboratory of consumption, an arena of concentrated consumption in which the intensity of meaning which consumption commands is graphically highlighted; although it provides what Gottdiener (2001) calls an 'overarching motif of consumerism, this process should not be assumed to be entirely passive. For this reason it is worthwhile reflecting on the psychological dimension of the cruise experience, as demonstrated, for example, in the work of Berger (2004) who defines cruise ships as temporary floating utopias; as 'no places' where social pathology and social strife are invisible and where choice is the primary currency, thereby legitimising a world in which choice is a dominant mode of social reproduction. For Berger this is a psychological process. There is something about the otherworldly setting of the cruise experience and the fact that in a sense it is not restrained by place, that effectively puts the person at the centre of their own experience. Cruise ships suggest to cruisers that they are leading 'the good life'. Yes, this is an escape but it is also a form of self-affirmation: a place for meaning-making and belonging.

Of course, it is notoriously difficult to research the meanings with which consumers endow the consumption of leisure and tourism. In his seminal work, McCracken (1990) for example, notes the fact that meaning is in constant transit. For McCracken consumers are engaged in an ongoing process of self-definition, and a key dimension of this is the systematic appropriation of meaning through consumer goods. In this respect, goods and indeed experiences are vital agents of social continuity and change. We can thus understand this as 'self-work' in the sense that such a process never ceases; through their consumption the individual is engaged in a cultural process, the purpose of which is to 'complete the self (p. 88). In facing such challenges, it is important to be methodologically agile, and in the remainder of this article I will thus reflect upon my own autoethnographic experiences of cruising as a form of self-work whilst addressing the broader significance of cruising as a form of twenty-first century tourism consumption. I will thus engage with the meaning of the cruise experience through my own eyes, while seeking to address the significance of the processes that underpin that experience.

Autoethnography is a method that involves describing and analysing personal experiences in order to understand cultural experience (Adams, Holman Jones, \& Ellis, 2015). As an approach, it acknowledges that culture should be located 'in the private sphere of the self' (Chang, 2008). What I present here is thus less of an 'ethnographic memoir' and more of a 'self-narrative' conducted in a particular social context. I recognise that personal worlds form part of larger social worlds and that consumers are 'enmeshed together in a complex process of mutual definition and construction' (Muncey, 2010, p. 15). Furthermore, noting that Dolnicar and Ring (2014) and Bosangit et al.'s (2015) contention that research has neglected how it is that consumers construct events as personally meaningful, the contention is that an autoethnographic approach offers an useful lens in this regard. 
insights provided below emanate from participant observations on four cruises across three mid-range cruise lines, MSC, $\mathrm{P} \& \mathrm{O}$ and Royal Caribbean. In each case I used techniques of observation, collecting and making a record of data to try understand what cruising could tell us about the contemporary tourism experience. It is important to note, that, in the autoethnographic tradition, I embrace my own personal connection to my data. In other words, it is not just the 'product' that cruise passengers are presented with that interests me, but also the way that I, as a consumer, personally engage with the cruise 'product' and attach meanings which in turn represent a kind of positioning between my self and the structures that impinge upon that self. Through this process, I endeavour to begin to understand the broader cultural significance of cruising.

\section{Cruise consumption, social change and 'self-work'}

Over the past twenty years or so people and networks of communication have been connecting in more and more complex ways to the extent that Urry (1998) describes a 'hollowing out' of traditional societies. More recently authors have debated how it is that consumers seek to navigate what have arguably become increasingly precarious life-worlds (Brown, 2015). For Brown all conduct is economic conduct; all spheres of existence, including tourism, are framed and measured by the economic and the crass commodification that this infers. Human beings thus effectively exist as 'market actors', desensitised, 'to the bold contradiction between an allegedly free-market economy and a state now wholly in service to and controlled by it' (Brown, 2015, p. 40). McGowan (2016) argues that capitalism dominates because it mimics the structure of our desire while hiding the trauma that the system inflicts upon us. For McGowan then being a consumer is about the experience of never finding satisfaction, but relentlessly pursuing it through the signification that consumption generates so that the repetition of loss that this involves brings with it its own satisfaction.

In what remains of this article I want to consider the suggestion that the cruise ship experience is the quintessential manifestation of this process. It is under such circumstances that the cruise ship can be said to be emblematic of a particular strand of social change and offers what is in effect, a laboratory in which such a transition is visibly concentrated. The appeal of the cruise ship lies in its ability to take passengers from place to place in a time-efficient fashion. And yet at one and the same time the nature of the experience of these places is necessarily diluted and homogenised. The experience that the passenger consumes, at least appears to be, a highly manufactured one. The point here, however, is not so much that the places or cultures passengers experience on a cruise ship are necessarily 'inauthentic' but more that they are inevitably partial in nature, to the extent that the ports of call at which a tourist disembarks become distractions along the way. They are packaged as 'excursions' and thus that is what they become: excursions from the reality of everyday life which perpetuates a sense, arguably an illusion of desire in a world of consumption where satisfaction can never actually be reached. But more than this, cruise ships recreate a kind of de-territorialized everydayness, a kind of consumerist stability that serves to reassure the self. Indeed, my own contention here is that the cruise ship experience tells us something significant about the nature of 'self-work' and how the tourist experience contributes to a sense of self.

As a means of addressing the above concern I want to briefly consider my own relationship to the cruising experience and the positionality it implies. First of all, I am a sociologist of consumption, so of course I am intrigued by the particular settings in which people consume and why. But my interest in cruise ships and my attraction to them is more than simply about my going on a 'busman's holiday'. When booking my cruises I did so many months in advance. I am someone who places a lot of emphasis on holidays which I plan like military operations. I mostly go on holiday alone, and spend many months imagining how I will fully utilise the me-time my holiday allows me. For me the anticipation of the event is half the 
satisfaction. I have usually kept the fact I am going on a cruise a secret amongst my university colleagues, because their cultural capital is such that they would think negatively of my doing so. When I think about why cruises fascinate me so I conclude that this is partly the result of my social and class background. My family were aspirational working-class. I was brought up in a New Town, Bracknell, in southern England, a place where everybody seemed to be 'keeping up with the Jones's', at a time, the 1980s when the political context encouraged an individualistic mindset. People liked to display their success whether it be through a new house, a Sony Walkman, a new bicycle at Christmas or by going on a package holiday abroad. It was this way of thinking that brought me to my fascination with consumption and how we use it to construct who it is we are. As for cruises, I had long imagined them as a form of aspirational luxury: as enchanted spaces. But my holiday is not just a way of reviving myself after a hard-working year, it sits at the centre of my year. In this sense I am perhaps an exaggerated version of the archetypal cruiser, locating myself in the apparently consumerist idyll that a cruise ship apparently provides. Most importantly, I bring to my cruising experience an open mind. I am intrigued by the appeal that cruising has for consumers, but do not preconceive this appeal negatively. My focus is on what cruising means for how cruisers construct meaning and what this tells us about the role of consumption in the process of social change.

\section{A day on board ship}

As a means of beginning to address the above, I will now present a brief autoethnographic composite of a typical day on a cruise ship, incorporating reflections on my own experiences and meaning-making during four cruises, but primarily as means of understanding a setting that maximises the opportunity to consume while minimising the ability of that experience reaching the point of satisfaction. The composite also serves the purpose of demonstrating the deterritorialised nature of the cruise experience.

I arrive at the destination airport, having noticed, if their excited chatter is anything to go by, that a number of fellow passengers were close by me on the plane to be picked up by one of a number of cruise liner coaches. This process is obviously highly rehearsed - there are dozens of cruise representatives ready to greet us. I can see the ship in the distance. The sheer awe-inspiring size of it puts a smile on my face: I look forward to the comfort and escapism ahead and there is a communal sense of anticipation and positivity in the air and yet a vague feeling of uncertainty. I have been imagining this moment, this opportunity to escape and just to be, for several weeks, if not months, and now the time has come, but will it give me the peace of mind that I so need? My fellow passengers and I are dropped off by the driver outside a hanger-like building, but fortunately the boarding process is streamlined and I am surprisingly on board the ship within twenty minutes. The only thing missing is my luggage which will be dropped off outside my cabin later by a crew member. My feeling is one of considerable anticipation: if being about to grasp my moment of genuine relaxation. I am given my own cabin card which doubles as a key and a payment card. The ship is cashless so for any purchase I simply pass the crew member my card (although at $15 \%$ the compulsory tip is on the hefty side). I wonder to myself how this apparent freedom from the control of money might mean for my spending patterns. Everything from the bar, to excursions, to the endless range of onboard activities, seem to be at my disposal for immediate gratification. This feeling is intensified by the fact that the cruise company have 'given me’ $£ 150$ cashback on my card, thereby giving me the arguably misguided impression that the money I am spending isn't even my own.

Once on board I am unable to take residence in my cabin which is still being prepared and am encouraged instead to seek out the all-day buffet which is taking place in one of the ship's eight restaurant spaces. The choice of food available to me is immense and the atmosphere is chaotic: I feel rushed and somewhat anxious as I seek out a table. It's quite tricky to get into a holiday 
mindset when so many people are literally in the same boat. The sheer number of people around me and the volume of voices is quite overwhelming. More worryingly whilst there I am obliged to enter into a maelstrom of discussions with waiting staff as to whether I might want to 'choose' to purchase a drinks package. These packages are sold on the basis that they make the consumer's experience cheaper and easier. And yet the choice is more limited than it might at first seem: so the opportunity to drink as much beer as you like, for example, is limited to one fairly uninspiring brand. I'm mildly irritated because I certainly wouldn't choose to drink this beer at home. Meanwhile, the reality is that the financial gains to me individually are at best marginal and it strikes me that what this experience actually does is put me in the invidious position of having to make decisions and thus effectively work for my own recreation, at exactly the time I am most desperately craving the relaxation to begin. I have no choice but to choose a package and thereby get rid of the stress that all this thinking is causing.

About an hour later I get into my surprisingly spacious cabin which is released at $2 \mathrm{pm}$. I had chosen my cabin (with balcony) online three whole months earlier and this had fed directly into a process of ongoing anticipation. In moments of boredom at work I would mindlessly click on my cruise ship bookmark and begin to imagine what it might be like to be there rather than in the mundane surroundings of the office. In such moments, I would think much more about the atmosphere on the ship than I do about the places it will be docking in, as I have already been to more than half of those already. It's more the sense of well-being and not having a care in the world that I look forward to. As for my cabin, I took the risk of picking one that is slightly bigger and of more an irregular shape than the norm, but located in a less than an ideal position close to the lifts and the potential noise that this might bring with it. But the risk seems to have paid-off, the cabin is quite big and less galley-like than most. I lie back on my bed and take it all in, wondering to myself: is this good enough? I'm quickly bored and so I go for a walk around the ship. Within five minutes, I am lost as my mental map struggles to differentiate between one level and another.

I attend the evacuation drill. This is not the serious and focused event that I would have imagined. Indeed, for some of the staff present it appears to be a piece of choreographed fun. In a way it's fun that isn't fun at all. I think to myself that this isn't the place to be entertained. During the remainder of the cruise I reflect on the role of the crew, and particularly those responsible for meeting the passengers' entertainment needs. The staff are responsible for implementing the vision of recreational bliss that a cruise ship perpetuates (even if this involves undermining the practical value of an evacuation drill) and this isn't always easy. It becomes clear that the ship is dominated by routine. There is some reassurance to be found in that but it feels like this only goes so far. Already, I am experiencing a kind of emptiness; an uncertainty as to whether this place can deliver the freedoms I want of it.

It's time for the ship to depart. I stand and wave goodbye to hundreds of faceless well-wishers none of whom are there for me. What's of interest to me at this point is that if I am escaping it's these people or at least what they symbolise, from which I escape: I smile to myself in anticipation of the time I will have to be free of obligated social interaction. I reflect on how it is that feeling says something more profound about me than I had imagined it would. I am alone; anonymous even. And yet the place I'm in seems to be encouraging me to think about who I am rather than providing me with the escape from who I am that I originally intended.

I pass on the opportunity of sipping a glass of champagne (this would have been charged to my cabin). I prepare for dinner. I am eating in the first of two sittings. It's a formal night. This means black tie. But surprisingly I'd say only around half the guests are conforming to this expectation. They are apparently enacting their freedom to choose. I share a dinner table with five other guests none of whom I have met before. I guess that for some passengers this meeting with strangers and sharing of the experience is what cruising is partly all about and for others it would be their idea of hell. I sit somewhere in the middle, but the sociologist in me means I am intrigued. My fellow diners regale me with tales of their previous cruise adventures which clearly constitute a badge of 
pride in this environment. We chat, but it's clear we have little in common. Afterwards, I consider my entertainment options: the 4-D cinema perhaps or the Formula One simulator? In the end, I walk the length of the ship to take my seat at the theatre to watch the first of what are nightly shows. The show, based around Broadway musicals apparently, really isn't my kind of thing, but there's something about the event and the fact that it demands so little of me that I relish. I would never normally listen to this kind of music, but I actually enjoy the performance independently of the music: there is something quite soothing about its inherent positivity and the fact, I guess, even as a lone traveller, it means I can be part of something for a while.

I visit a couple of bars (there are eleven to choose from), aimlessly walking through the ship casino on the way, none of which are as busy as I expect. I also pass an additional restaurant that I didn't know existed. It has the name of a celebrity chef attached to it and you can apparently book it should you be prepared to pay an extra charge for the privilege, and as an alternative to your main restaurant allocation. I sit for half an hour in a bar where a pianist and a singer perform, apparently only being half-watched by their audience. As the cruise goes on I end up returning here every night for a night cap. There is something about the surroundings of the bar and more importantly the duo that perform there every night that I find oddly reassuring: their music isn't particularly inspiring but the mere act of being there provides a way of marking the end of another day on board. This word reassurance is important. I feel vindicated by the place in which I find myself. I can just be for a while. I watch the world going by and wonder if the sense of release that I had imagined prior to my ship was really as marked or 'real' as I had imagined. Might I in fact, get bored with all this? I then retire for the night, hopeful that the magic of the ship will hit home more noticeably in daylight.

The next morning, I take a formal breakfast in the restaurant. I order from the menu. At one point, I have cause for complaint because my fairly straightforward breakfast is taking a long time to arrive. When I ask the waiter how long my breakfast will be he responds in a surprisingly nervous fashion: a look of panic crosses his face. His colleague is observing this and tells me, 'He's afraid for his contract', highlighting the tenuous nature of the working conditions that most crew members are forced to put up with.

I have avoided the formal cruise excursions on offer, although later in the week I do partake in one to a shopping district/area of architectural interest that would be difficult to reach independently. This involves an interesting diversion 'backstage' for me and my fellow excursionists on the way to the coach, where we momentarily pass through what is clearly a staff area of the ship as indicated by a prominent sign that reads: 'Smile and greet; Make the difference; Involve yourself; Lead by example; Enhance guests' experience'. But on the first morning I am taking a taxi to the biggest mosque in the city. After that I walk to a local market and take advantage of some of the street food on offer. I look around and most people appear to be passengers I recognise from the cruise. I then take a taxi back to the ship, going through security before returning to my cabin to pick up a book. I have been preparing for my holiday and for me the freedom to lie back and read a novel (I save all novel reading for my vacation) which to me represents the ultimate form of relaxation. I have been imagining this moment for months now: one of the ways I do this is by methodologically collecting novels that I plan to read on board. This is a big part of the build-up to my holiday. I bring six or seven books with me. And in the months previously they provide a medium through which I can imagine the calm peaceful space that I have in front of me. I literally line my books up and smile to myself: living the holiday before I have even physically got there. It's the prospect of my trip wherein my imagination runs riot. I find myself a relatively quiet spot beside the pool to escape from the world around me. But it's quite noisy and I worry about saving my seat should I need to get some food or a drink. I feel that sense of escape, and of release at last, but cannot help wondering to myself: 'How long will it last'? I fall asleep. Alas, the book didn't grab me as much as I'd hoped. But there is always tomorrow isn't there? 


\section{Beneath the 'total institution'}

What I have described above can certainly be described as a 'choreographed environment at sea' (Klingmann, 2007), an environment that is, in many respects, highly rationalised and controlled. There are a number of common characteristics to the experience. The basic product on offer is comparable from one cruise ship operator to another. Key elements include a choice of internal and external cabins with balconies, regular meal time 'sittings', a wide range of overly-expensive port excursions, on-board organised activities such as fitness classes or ice sculpture, the pivotal role of the theatre experience and a whole range of other common facilities such as a sports pitch, library, casino, spa, gym, café, numerous pools, the ritual of having to seek out a sunbed on sea days, restaurants and bars, video arcade, entertainment lounge and dancefloor, cinema, a children's/youth club, and a mini-shopping mall. This uniformity of consumer-driven experience is mirrored by the rationalised processes that the passenger is taken through from embarkation, to card payment for all services, to early or late dinner settings.

But what I think is more interesting here is what my experiences tell us about self-actualisation and specifically, the degree to which they fulfil their promise as spaces in which the self can be buttressed. My over-riding feeling in seeking to analyse the experience was one of vexation. Yes, the thought of the cruise and the time and space that the ship allowed me 'just to be' was welcome, but the irony was rather than losing myself, I tended to spend a lot of time reflecting inwardly upon my self. This was in part due to the fact I was travelling alone, but it was also no doubt the product of the fact that I was constrained in what was a de-territorialized space. This space was defined but also confined by consumption, it was the only space available to me, certainly on sea days. I felt as though I was able to make my own choices in what I did on the ship, but none of them brought me to a point where I felt totally at ease or fulfilled. Rather, mild anxiety was my cruise norm. I felt like I was engaged in a process where I was determinedly seeking to demonstrate to myself that I belonged and that I could, if I looked hard enough, find a sense of well-being in this space.

What does this tell us about the nature of cruise-based self-work? As Kim, Sullivan, and Cardona Forney (2007) put it, the consumer is no longer content with the stimulation provided by the act of purchase or consumption: the process of symbolic consumption arguably needs to be more pro-active so that the consumer him or herself is at its heart and so that he or she is provided, albeit temporarily, with a 'new me'. In reflecting on my own cruise experience, this analysis appears to be partially correct. My engagement with cruising was certainly pro-active in the sense that it gave me a palette upon which self-work was enabled. For me, the cruise ship became a space in which the self-inducing properties of consumption were intensified, while the feeling of this not ultimately being satisfying was magnified as much as the feeling of escape that proceeded it. What this meant in terms of my own sense of meaning construction was a feeling that on board ship anything was possible: that this placeless space was there for me to maximise my relation and thus to explore my own well-being: a place where I could belong and where I could belong anonymously, where I can feel 'total involvement with life' (Csikzentmihalyi, 2002; Mitrasinovic, 2006). This wasn't escapism as such. It was more about the sense that the cruise ship provided the space in which I was able to live a life how I imagined life to be. To put this another way we might agree with McCracken's argument that culture is constantly played out through goods and that these are therefore essential to how we construct our lives. But when I reflect on this process my conclusion, as McGowan (2016) suggests, is that all this actually achieves is an illusory satisfaction of the psyche that can never truly realise its desire. The meanings that we produce as consumers are real, intensively real given their experiential nature, and yet ironically less real in the sense that such experiences reinforce the ideological boundaries within in which such meanings are produced.

Cruise ships succeed on the basis that they provide an aura in which the world of luxury is attainable on a relatively modest budget. Superficial scrutiny might lead us to conclude that the cruise ship provides the consumer with nothing more than a stage for spectacular consumption 
and escapism. But there is a degree of choice here and although the atmosphere is 'naturalised' the consumer enters this naturalised space knowingly and with personalised intent: the cruise ship provides self-oriented experience or at least the perception of such. In my own experience this was certainly an environment that puts the individual at the centre of his or her own narrative and herein lies its immersive effect.

Given my last statement, I want to suggest that a reading of the cruise ships as a total institution (Ritzer, 2010) is, indeed, at least partly misleading and dependent upon a surface reading of cruise ships and one that neglects significant psycho-social dimensions of how that setting is actually realised. While it is true that the cruise passenger experience obliges the consumer to behave in a predetermined fashion and while it is also true that cruise ships can be said to have in recent years come to take on some of the characteristics of non-cruise mass tourism, such an approach effectively neglects the meaning-making aspect of the cruising experience. My contention then is not that the consumer is the product, in the somewhat cynical way that Pine and Gilmore (1999) suggest, namely that the skilled business person can effectively manipulate the consumer experience in order to give the consumer the sense that they are somehow experiencing a life-changing experience, but that the consumer is increasingly at the centre of his or her own partial process of self-construction. The cruise ship provides the consumer with a stage and a narrative through which they can access a palatable version of themselves that is rooted in their ability to consume the freedom that they perceive that this form of consumption provides. But what is crucial here is that such a canvas simultaneously intensifies the potential for the ideological power of consumption: the sense of self-work that cruising induces reproduces a kind of in-built loyalty, a commitment to the benefits of the experience, that far outweighs what it can offer in practice.

What I have argued up to this point is that the cruising experience is less rationalised than it may appear on the surface and that the albeit limited options with which a cruise presents its passengers at least have the potential for proactive forms of exploration on the part of the consumer. What I am not arguing here, however, that the cruise ship passenger is entirely free of ideological constraint, far from it, but that the experience of being a cruise ship passenger might tell us something about how what it means to be a consumer is changing and that the increased popularity and apparent democratisation of cruising reflects this. In effect, my argument is that the ideological power of spaces for consumption are becoming more subtle than in the past. This is achieved by a pronounced focus on the experience of the consumer and a broader process in which there has been a shift away from the specific consumption of products to consumption as a temporal, partial, experiential and an often placeless process of self-endowment. Of course, other forms of experiential leisure and tourism activity such as amusement parks, museums, or indeed all-inclusive tourism resorts, might well offer the same potential for bounded self-endowment. All these spaces are increasingly prone to focus on not just providing a product to be consumed, but on putting the self at the centre of that product. To an extent we can assume that the motivations behind such a transition to experiential consumption are in part cynical and simply a sophisticated way of capturing the attention of the consumer. What makes cruise ships, more interesting, however, is the fact that such space is corralled over longer periods of time and thereby intensifies the placeless nature of the opportunities for self-work that they provide. Such spaces provide the consumer with a context that effectively obliges them to use experience as a source of self. But the irony of that space is that the intensely placeless nature of the cruise ship, the way it concentrates the self in the way other more escapist and time-bound modes of tourism cannot, ties us very our closely to our selves and thus provides a means of playing out the underpinning values of a changing, though still fundamentally consumer-driven, society.

Although we might assume that the heyday of consumption and its role in identity construction might be located in the 1990s in an era when economics meant our consumption was less constrained than it is today (given we appear to live in a world of perpetual economic crisis), this is not, arguably, in fact the case. The power of consumption is rendered greater by its shift to an 
experiential plain where the individual narrative is closer to the surface than it ever was in the past. My own anticipation of the cruises above reflected a deep-seated need to live a life, a life at least momentarily different to the one I experience in the day-to-day. The consumer does not 'find' him or herself on the cruise ship, what he or she clings on to is a partial and temporary from of self-discovery, a kind of personal peacefulness that could and will be taken away at any minute, but one which is nonetheless highly anticipated before the event, and quite possibly a matter for regret afterwards. In this sense the pleasures that these forms of experience provide come at a cost. The feeling of intense selfhood that they bring are ultimately offset by a longer lasting sense of emptiness and uncertainty. Indeed, it is the intensity of this sense of selfhood that in turn intensifies the consumer's pursuit of fulfilment. He or she may not feel satisfied or self-realised by a cruise, but the prospect that he or she might be never goes away.

\section{Conclusion}

In one sense, the consumer of cruises will almost inevitably be disappointed and or bored: regardless of how many activities are made available to passengers. The constrained parameters within which cruise ships inevitably operate, bound the experience in mental as a well as physical form. Meanwhile, as Rojek (1994) points out, the tourist experience is often anti-climactic once the consumer steps too close to the scene they created in their imaginations. And yet, like the serial cruiser, we soon return again to the scene apparently undiminished; perhaps convinced that the moment of satisfaction can be reached after all. As Illouz puts it, 'consumption is the result of the cyclical passage from excitement to comfort and from there to boredom, which in turn results in a new cycle of excitement, comfort and boredom' (p. 391). The cruising experience professes the benefits to be had from freedom, mobility and choice. It effectively provides what de Botton (2009) describes as form of 'temporary forgetting'. The consumer is desperate to avoid boredom at all costs. The cruise ship, at least superficially appears to negate any such possibility. It seeks to make any such state of affairs an impossibility. And yet, talking form an autoethnographic perspective, the accumulative effect, is exactly what the consumer seeks to avoid. The sheer multitude and seductive possibilities for constant gratification ultimately leave the consumer disoriented. He or she is likely to be bored by the vast array of choices set before him or her: because ultimately such choices do not constitute any kind of a choice at all.

The cruise ship is thus indicative of a broader trend towards self-authored tourism in which the consumer is not only the product of his or her own consumption, insofar as the cruise experience allows the consumer to construct a consumer-driven version of themselves through the setting the cruise ship provides. Ultimately such an experience simply serves to perpetuate the consumer's need to find a form of self-actualisation that consumption cannot actually, ultimately, be relied upon to provide. In fact, more than that its very success depends on its inability not to provide such satisfaction (McGowan, 2016). It is for this reason that the cruise ship passenger and indeed the consumer more generally, keeps coming back for more. The individual is thus both actor and audience in his own drama 'his own' in the sense that 'he constructed it, stars in it, and constitutes the sum of the audience' (Campbell, 1987, p. 78).

The cruise ship offers a means by which the consumer can re-assert his or her faith in time and its ability to provide new means of self-expression and assertion. Or so it seems. A paradox exists here that may sit at the heart of the tensions borne in the contemporary relationship between consumption and identity (Moran, 2014). That is, as I note above, this ability to self-actualise is inevitably limited precisely because consumption is not about fulfilling self but about escaping from it. The flaw in cruise ships therefore appears to lie in their ability to give the impression that you as a consumer can discover and live a narrative of the consumer's own choosing. But the cruise ship performs luxurious escapism in such a way that while it offers self-discovery on the one hand, on the other, it takes it away, by closely defining the routes through which selfdiscovery can be achieved and making their actual achievement an impossibility. As such, the 
cruise ship passenger becomes an identity tourist, not in the post-modern sense of free-wheeling fragmentation, but insofar as the pleasures of experience become nothing more than an unrealisable end in themselves. We define ourselves not by who we are but through the nature of what it is we experience. And herein lies an indication of where the world of consumption may be going and the role that tourism may play in its maintenance. The stories that consumerism provides us with are more compelling, more immersive, more 'real' than they have ever been: we are where we travel. This operationalises an unheralded degree of ideological control at a point in history in which tourism has paradoxically and ironically become less about the individual than it ever was before.

\section{Disclosure statement}

No potential conflict of interest was reported by the author.

\section{Notes on contributor}

Steven Miles is Professor of Sociology at Manchester Metropolitan University and author of Retail and the Artifice of Social Change (Routledge; 2015). Other key publications include, Consumerism as a Way of Life (Sage; 1998), Youth Lifestyles in a Changing World (OUP; 2000) and Spaces for Consumption: Pleasure and Placelessness in the Post-Industrial City (Sage; 2010). He is currently completing a book, The Experience Society for Pluto. He is Editor-in-Chief of the Journal of Consumer Culture.

\section{ORCID}

Steven Miles (iD) http://orcid.org/0000-0002-3317-1151

\section{References}

Adams, T. E., Holman Jones, S., \& Ellis, C. (2015). Autoethnography: Understanding qualitative research. Oxford: Oxford University Press.

Berger, A. (2004). Ocean travel and cruising: A cultural analysis. London: Haworth Hospitality.

Bosangit, C., Hibbert, S., \& McCabe, S. (2015). 'If I was going to die I should at least be having fun': Travel blogs, meaning and tourist experience. Annals of Tourism Research, 55, 1-14.

Breathnach, T. (2006). Looking into the real me: Locating the self in heritage tourism. Journal of Heritage Tourism, $1(2), 100-120$.

Brown, W. (2015). Undoing the demos: Neoliberalism's stealth revolution. New York: Zone Books.

Campbell, C. (1987). The romantic ethic and the spirit of modern consumerism. Cambridge: Wiley-Blackwell.

Chang, A. (2008). Autoethnography as method. London: Routledge.

Collareo, P. L. (2003). The sociology of the self. Annual Review of Sociology, 29, 115-133.

Cremin, C. (2011). Capitalism's new clothes: Enterprise, ethics and enjoyment in times of crisis. London: Pluto.

Cruise Lines Association. (2018). [online] Retrieved from https:/www.cruising.org/docs/default-source/research/ 2016_clia_sotci.pdf

Csikzentmihalyi, M. (2002). Finding flow: The psychology of engagement with everyday life. New York: Rider.

de Botton. (2009). A week at the airport: A heathrow diary. London: Profile.

Dolnicar, S., \& Ring, A. (2014). Tourism marketing research: Past, present and future. Annals of Tourism Research, $47,31-47$.

Elliott, A. (2016). Identity troubles. London: Routledge.

Gottdiener, M. (2001). The theming of America: American dreams, media fantasies, and themed environments. London: Routledge.

Kim, Y.-K., Sullivan, P., \& Cardona Forney, J. (2007). Experiential retailing: concepts and strategies that sell. New York: Fairchild.

Klingmann, A. (2007). Brandscapes: Architecture in the experience economy. Cambridge: MIT Press.

Kolberg, S. (2016). Constructing a 'democratic' dreamworld: Carnival cruise ships and an aesthetic of optimism. Journal of Consumer Culture, 16(1), 3-21.

McCracken, G. (1990). Culture and consumption: New approaches to the symbolic character of consumer goods and activities. Bloomington: Indiana University Press. 
McGowan, T. (2016). Capitalism and desire: The psychic cost of free markets. New York: Columbia University Press. Miles, S. (2010). Spaces for consumption: Pleasure and placelessness in the post-industrial city. London: Sage.

Mitrasinovic, M. (2006). Total landscape, theme parks, public space. Aldershot: Ashgate.

Moran, M. (2014). Identity and capitalism. London: Sage.

Muncey, T. (2010). Creating autoethnographies. London: Sage.

Noy, C. (2004). This trip really changed me: Backpackers' narratives of self-change. Journal of Tourism Research, 31 (1), 78-102.

Pine, B. J., \& Gilmore, J. H. (1999). The experience economy: Work is theater and every business a stage. Cambridge: Harvard Business Review Press.

Prentice, R. (2001). Experiential cultural tourism: Museums and the marketing pf the new romanticism of evolved authenticity. Museum Management and Curatorship, 19, 5-26.

Ritzer, G. (2010). Enchanting a disenchanted world: Continuity and change in the cathedrals of consumption. London: Sage.

Rojek, C. (1994). Ways of escape: Modern transformation in leisure and travel. London: Rowman and Littlefield.

Selwyn, T. (1996). The Tourist Image: Myth and Making in Tourism. Chichester: John Willey.

Smith Maguire, J. (2008). Fit for Consumption, Sociology and the Business of Fitness. London: Routledge.

Urry, J. (1998). Contemporary transformations of time and space. In P. Scott (Ed.), The globalization of higher education (pp. 1-17). Buckingham: SRHE/Open University Press.

Wood, R. E. (2008). Caribbean cruise tourism: Globalization at sea. Annals of Tourism Research, 27(2) 345-370. 